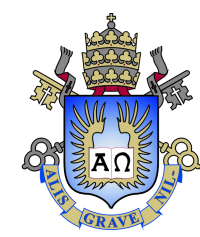

Rodolfo Dinis Rigato

\title{
Disentangling Aggregate and Sectoral Shocks Using Price Microdata
}

Dissertação de Mestrado

Dissertation presented to the Programa de Pós-graduação em Economia da PUC-Rio in partial fulfillment of the requirements for the degree of Mestre em Economia .

Advisor: Prof. Carlos Viana de Carvalho 


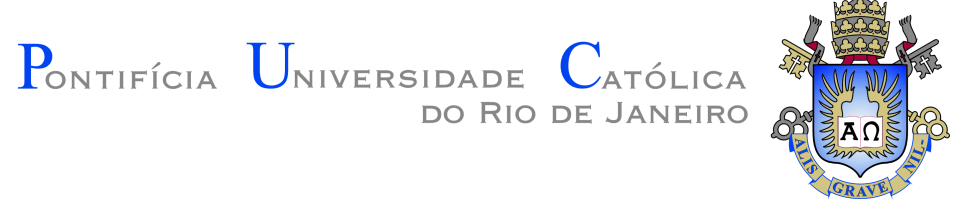

Rodolfo Dinis Rigato

\title{
Disentangling Aggregate and Sectoral Shocks \\ Using Price Microdata
}

Dissertation presented to the Programa de Pós-graduação em Economia da PUC-Rio in partial fulfillment of the requirements for the degree of Mestre em Economia. Approved by the undersigned Examination Committee.

\author{
Prof. Carlos Viana de Carvalho \\ Advisor \\ Departamento de Economia - PUC-Rio \\ Prof. Marco Antonio Cesar Bonomo \\ Insper - Instituto de Ensino e Pesquisa
}

Prof. Eduardo Zilberman

Departamento de Economia - PUC-Rio

Prof. Augusto Cesar Pinheiro da Silva

Vice Dean of Graduate Studies

Centro de Ciências Sociais - PUC-Rio

Rio de Janeiro, April the 16th, 2018 
All rights reserved.

\section{Rodolfo Dinis Rigato}

B.A. Economics, Insper, 2015

Bibliographic data

Rigato, Rodolfo Dinis

Disentangling Aggregate and Sectoral Shocks Using Price Microdata / Rodolfo Dinis Rigato; advisor: Carlos Viana de Carvalho. - Rio de janeiro: PUC-Rio , Departamento de Economia , 2018.

v., 39 f: il. color. ; $30 \mathrm{~cm}$

Dissertação (mestrado) - Pontifícia Universidade Católica do Rio de Janeiro, Departamento de Economia .

Inclui bibliografia

1. Economia - Teses. 2. Macroeconomia - Teses. 3. Ciclos Econômicos;. 4. Choques Agregados;. 5. Choques Setoriais;. 6. Fixação de Preços;. I. Carvalho, Carlos Viana de. II. Pontifícia Universidade Católica do Rio de Janeiro. Departamento de Economia. III. Título. 
To my parents, Otelo e Fátima, and my future wife, Camila. 


\section{Acknowledgments}

I thank my advisor, Prof. Carlos Viana de Carvalho, for the extraordinary dedication to this project, and Prof. Marco Bonomo for the extremely helpful insights.

I also thank my parents, Otelo and Fátima, without whom I would have never developed such an interest for academic research, and my future wife Camila for the unparalleled support. 


\section{Abstract}

Rigato, Rodolfo Dinis; Carvalho, Carlos Viana de (Advisor). Disentangling Aggregate and Sectoral Shocks Using Price Microdata. Rio de Janeiro, 2018. 39p. Dissertação de mestrado Departamento de Economia , Pontifícia Universidade Católica do Rio de Janeiro.

We estimate the volatility of aggregate and sectoral shocks, as well as their contributions to business cycles fluctuations, using price setting data. The key idea is that sector-specific innovations are associated with the dynamics of price setting statistics, such as average size of price adjustments, within a single economic sector, while the volatility of aggregate disturbances can be inferred from the correlation of these statistics across different sectors. Therefore, price setting data provides useful information about the nature of economic fluctuations. We employ a rich price setting model in which firms face not only menu costs, but also informational frictions and estimate it using Simulated Method of Moments and data from the UK. We find that sectoral shocks are considerably more volatile than their aggregate counterparts.

\section{Keywords}

Business Cycles; Aggregate Shocks; Sectoral Shocks; Price Setting; 


\section{Resumo}

Rigato, Rodolfo Dinis; Carvalho, Carlos Viana de . Separando Choques Agregados e Setoriais Usando Microdados de Preços. Rio de Janeiro, 2018. 39p. Dissertação de Mestrado Departamento de Economia , Pontifícia Universidade Católica do Rio de Janeiro.

Este trabalho estima a volatilidade de choques agregados e setoriais, bem como suas contribuições para flutuações econômicas, usando microdados de preços. A ideia central é que inovações setoriais estão associadas com a dinâmica de certas estatísticas, como tamanho médio de reajustes de preços, de um setor econômico específico, enquanto a volatilidade de choques agregados pode ser inferida pela correlação destas estatísticas entre setores diferentes. Portanto, microdados de preços contêm informação sobre a natureza dos ciclos econômicos. Emprega-se aqui um modelo de fixação de preços no qual firmas enfrentam não somente custos de menu, mas também fricções de natureza informacional. O modelo é estimado usando o Método dos Momentos Simulados e dados do Reino Unido. Encontra-se que choques setoriais são consideravelmente mais voláteis que choques agregados.

\section{Palavras-chave}

Ciclos Econômicos; Choques Agregados; Choques Setoriais; Fixação de Preços; 


\section{Table of contents}

1 Introduction $\quad 11$

2 Related Literature $\quad 14$

3 The Model $\quad 16$

$\begin{array}{ll}3.1 \text { An Overview } & 16\end{array}$

$\begin{array}{ll}\text { 3.2 The Firms' Problem } & 17\end{array}$

4 Estimation $\quad 21$

4.1 Estimation procedure 21

4.2 Moments Used in the Estimation 22

4.3 Estimation Results 24

5 Computational Experiments $\quad 29$

6 Concluding Remarks $\quad 32$

7 Appendix A $\quad 36$

$8 \quad$ Appendix B $\quad 38$ 


\section{List of figures}

Figure 3.1 Optimal pricing policy shown as the boundary of the inaction region, for parameter values: $K=0.001, F=0.002$, $\mu=0.1, \rho=0.03, \sigma_{c}^{2}=0.05$ and $\sigma_{i d}^{2}=0.05$

Figure 4.1 Ergodic distribution when sectoral and aggregate shocks are absent, for parameter values: $K=0.001, F=0.002, \mu=0$, $\rho=0.03, \sigma_{c}^{2}=0.05$ and $\sigma_{i d}^{2}=0.05$

Figure 5.1 Sectoral output responses to $1 \%$ aggregate demand shocks for estimated parameter values.

Figure 5.2 Aggregate GDP responses to one time, unexpected aggregate shocks for estimated parameter values.

Figure 5.3 Real output volatility as a function of $\sigma_{a g g}$. The benchmark case refers to estimation results. 


\section{List of tables}

Table 4.1 Estimated parameters and standard errors for the single sector model.

Table 4.2 Model generated and data moments for single sector model 25

Table 4.3 Estimated parameters and standard errors for the multi sector model. Sectors are numbered as follows: 1) Foods, beverages and other agricultural products, 2) Manufactures and 3) Services. For example, $\sigma_{i d, 2}$ is the volatility of idiosyncratic shocks in the manufactures sector.

Table 4.4 Model generated and data moments for multi sector model. 28 


\section{Introduction}

Establishing whether macroeconomic fluctuations arise as a consequence of sector-specific or aggregate shocks, or some combination of these two flavors, is a question that lies at the heart of research on business cycles. Both approaches have been present in the literature since the earliest Real Business Cycles models ${ }^{1}$, and evidence on the empirically plausibility of these different approaches has the potential to provide important insights on the nature of business cycles.

In this paper, we disentangle both sources of macroeconomic fluctuations using price setting micro data. We are able to identify, using a structural model, the size of aggregate and sector-specific disturbances, measured as standard deviations, as well as each kind of shock's contribution for real output dynamics. Our database consists of the price quotes used to construct the United Kingdom's consumer price index, which allows us to to calculate several price setting statistics, such as frequency or average size of price adjustments, for any given set of economic sectors.

The key idea for inferring the sizes of aggregate and sectoral shocks from these statistics is as follows. Imagine that different economic sectors face not only independent sector-specific shocks, but also disturbances of aggregate nature. There is a continuum of combinations of aggregate and sectoral shocks' volatilities that are consistent with the time variation of price setting statistics for a given economic sector. Therefore, looking at the time variation of price setting statistics is not enough to disentangle these two sources of disturbances. However, the correlation of these statistics across different economic sectors allows us to pin down the exact combination of sectoral and aggregate innovations that are generating this dynamics. For example, if the mean size of price adjustments across different economic sectors displays high correlation, it is likely because this dynamics is being generated by a common source. That is, price setting data provides very useful, and yet unexplored information, as far as the authors' knowledge goes, about the nature of shocks that generate price fluctuations. Price setting data provides a complimentary

\footnotetext{
${ }^{1}$ Kydland and Prescott (1982), on the one hand, explain economic fluctuations using aggregate shocks only, while Long and Plosser (1983) rely on a multisector framework.
} 
approach to the industrial production data commonly used in the literature, as explained in chapter 2. Employing this information to estimate the magnitudes of sectoral and aggregate shocks is the main contribution of this paper. We find that sectoral shocks are significantly more volatile than their aggregate counterparts, by a factor that ranges from slightly less than 4 to more than 5 . As a consequence of this, simulations using our structural model indicate that aggregate output volatility would be only $7.7 \%$ smaller if aggregate shocks were shut down.

Our methodology consists in estimating a structural price setting model, as in Bonomo, Carvalho, Garcia and Malta (2018), using Simulated Method of Moments (SMM). The model features price setting firms that are subject to frictions of two different flavors. Despite facing standard menu costs, i.e., fixed costs that must be paid in order to adjust prices, firms also face a friction of informational nature. This friction takes the form of another fixed cost that must be paid in order to obtain full information about current economic conditions. We generalize Bonomo et al. (2018), however, by allowing our model economy to feature many economic sectors. This gives rise to a second contribution. We show that estimates of the standard deviation of aggregate shocks may have a considerable upward bias in the absence of sectoral shocks. The estimated volatility of aggregate disturbances shrinks by a factor of almost 5 when we move from a single sector to a multi sector framework. This happens because in order to fit the time variability of price setting statistics and the cross sectional dispersion of price changes, a single sector model requires very large aggregate shocks, which in our case may reach an unrealistically annual standard deviation of $20 \%$. By allowing sectoral shocks to do the job, this number falls to roughly $4 \%$, while sectoral shocks' standard deviations are as high as $21.5 \%$. Although estimates for aggregate shock volatility are almost mechanically expected to fall with the introduction of sectoral shocks, it is interesting that our estimated multi sector model generates quarterly nominal GDP volatility of $2.04 \%$, which is remarkably close to what is observed in the data for our sample period, $2.33 \%$, for UK.

Our third contribution is to show that there is significant heterogeneity in the size of frictions across sectors, which generates large differences in sectoral output responses to aggregate shocks. Both fixed costs, the menu cost and the cost of acquiring full information, may be approximately twice as large in some sectors than in others. This cross sectional heterogeneity in the severity of frictions generates a similar dispersion on the persistence of aggregate shocks effects on sectoral output, which may also reach a factor of 2. Nevertheless, when the sectoral outputs are aggregated into real GDP, the 
multi sector model behaves closely to a single sector model.

The paper proceeds as follows. Section 2 provides a brief review of related literature. Section 3 presents and explains the structural model that is going to be estimated, and section 4 provides an explanation of the data and estimation techniques we employ. Section 5 performs some computational experiments departing from estimation results. Finally, section 6 contains some concluding remarks. 


\section{2 \\ Related Literature}

This paper is related to two distinct branches of macroeconomic research. The first one is a literature that studies sectoral shocks as drivers of economic fluctuations and tries to quantify the relative importance of aggregate and sectoral disturbances. This literature dates back to Long and Plosser (1983), who develop a pioneering RBC model in which business cycles dynamics is generated exclusively by sector-specific shocks. Foerster, Sarte and Watson (2011) and Garín, Pries and Sims (2016) perform decompositions of fluctuations in sector-level output between the two types of shocks mentioned. Our paper differ from theirs in two directions. First, we use price microdata, rather than sectoral output time series, in order to perform such decomposition. This implies a very different outcome about the importance of aggregate shocks in output fluctuations. Second, we find that in the absence of aggregate disturbances, output volatility would decrease by a factor that is significantly smaller than previously found, around 7.7\%. Hovarth (1998), Dupor (1999) and Hovarth (2000) study dynamic properties of multi sector economies, e.g. when they are observationally equivalent to a single sector economy, or the conditions under which the law of large numbers is not strong enough for sectoral shocks to cancel out. Atalay (2017) finds evidence that intermediate inputs from different industries are complements for production, which enhances the importance of sector-specific shocks as business cycles drivers. We depart from these studies bt abstracting from input-output relationships between different sectors, for the sake of tractability.

The second branch of research related to this paper is one which aims to understand firms' price setting behavior. The modern research on price setting models in which firms face idiosyncratic shocks starts with Golosov and Lucas (2007). The authors show that a standard menu cost model calibrated to match price setting statistics, such as frequency of proce changes, cannot generate persistent effects of monetary shocks. They argue that the reason for this is that, after an aggregate shock takes place, the firms that reset prices are precisely those whose prices are furthest away from optimal values. This selection effects weakens aggregate effects of monetary innovations. Nakamura and Steinsson (2010) increment the model with sectoral heterogeneity and strate- 
gic complementarity, and show that these features increase significantly the persistence of monetary shocks on real variables. The model employed here is also able to generate these persistent effects, but relies on different mechanisms to do so, namely informational frictions, as in Bonomo, Carvalho, Garcia and Malta (2018).

The model employed here is essentially one of the many introduced by Bonomo, Carvalho and Garcia (2011). The authors develop several price setting models of increasing complexity, culminating in the menu cost and partial information model used in this paper. Alvarez, Lippi and Paciello (2011) study a similar model and provide analytic insights on its properties. Woodford (2009) also introduces a similar model, although informational frictions are modelled differently, using a rational inattention framework. 


\section{The Model}

\section{1}

\section{An Overview}

There are $N$ economic sectors, indexed by $j \in\{1, \ldots, N\}$, each one composed by a continuum of firms which maximize their expected flows of discounted profits subject to two distinct frictions. First, firms must pay a fixed menu costs, denoted $K_{j}$ and allowed to be sector-specific, in order to reset their prices. Such menu costs are standard in the state-dependent pricing literature, and are well-know for generating substantially long intervals between price readjustments. Second, not all information about a firm's profit maximizing price is freely available. In order to acquire full information about it, firms must pay different fixed costs $F_{j}$, also allowed to vary across sectors. In the absence of information gathering costs, the model would become a classic sS model, which has already been extensively studied in the literature ${ }^{1}$. Informational frictions generate interesting optimal policies which approximate time-dependent pricing when freely observable innovations become small ${ }^{2}$. Fixed costs in the problem will generate an inaction region in a suitably defined state-space introduced in the next section. A textbook treatment of models that feature inaction can be found in Stokey (2008).

It is notationally easier (although formally equivalent ${ }^{3}$ ) to imagine firms minimizing costs that arise from discrepancies between the price charged at instant $t$, denoted by $p_{t}$, and the profit maximizing price $p_{t}^{*}$. This cost is conveniently approximated by a quadratic function of the form $\left(p_{t}-p_{t}^{*}\right)^{2}$, which is standard in the literature.

The profit maximizing price $p_{t}^{*}$ follows a Brownian motion with three independent components: an idiosyncratic, a sectoral and an aggregate innovation. Needless to say, aggregate shocks affect all firms, regardless of the sector to which they belong, while there is a different sectoral shock for each sector

\footnotetext{
${ }^{1}$ Some contributions to this literature include Caplin and Spulber (1987), Caplin and Leahy (1997), Caballero and Engel (2007) and Gertler and Leahy (2008)

${ }^{2}$ Bonomo, Carvalho and Garcia (2011) and Alvarez, Lippi and Paciello (2011) provide insights for this result.

${ }^{3}$ See Bonomo, Garcia and Carvalho (2011)
} 
in the model, and firms belonging to the same sector are affected symmetrically by these disturbances. The idiosyncratic component is firm-specific and independent across firms. For the purpose of assessing the effects of monetary innovations over price setting dynamics, it is convenient to interpret aggregate shocks as nominal aggregate demand disturbances that arise from the conduct of monetary policy, although productivity may also have an aggregate component: the internet revolution etc. Firm- and sector-specific shocks may be interpreted as productivity fluctuations. A rigorous derivation of the model from a standard New Keynesian framework is drawn in appendix A.

The idiosyncratic component of the profit maximizing price is freely observable. The sectoral and aggregate ones, on the other hand, are not, requiring the firm to pay an information gathering cost, al mentioned above, in order to observe both of them simultaneously. We shall refer to the instants in which firms pay such a cost as information dates. Between two consecutive information dates, firms must form expectations about the paths of costly observable innovations. In the case in which both frictions are absent (information and price readjustment costs), firms optimally choose to keep their prices equal to $p_{t}^{*}$. The profit maximizing price $p_{t}^{*}$ is therefore also referred to as frictionless optimal price. A more complete description of the model is presented below.

\section{2}

\section{The Firms' Problem}

We first present the maximization problem of a single firm. The frictionless optimal price ${ }^{4}$ evolves according to

$$
d p_{t}^{*}=\mu d t-\sigma_{i d, j} d W_{i d, t}-\sigma_{s e c, j} d W_{j, t}-\sigma_{a g g} d W_{a g g, t}
$$

Above, the parameter $\mu$ is the deterministic growth trend of nominal aggregate demand. The profit maximizing price has thus a non-stochastic component which reflects the inflation rate of the economy. The uncertain part of $p_{t}^{*}$ is, as already mentioned, divided into three independent components. The idiosyncratic part is represented by the (standard) Wiener process $W_{i d, t}$, multiplied by a volatility $\sigma_{i d, j}$ which is allowed to depend on the sector $j$. This mean that firms belonging to different sectors may face unequally volatile idiosyncratic disturbances to $p_{t}^{*}$. Sectoral and aggregate innovations take the form of standard Wiener processes $W_{j, t}$ and $W_{a g g}$ with respective volatilities

\footnotetext{
${ }^{4}$ The dependency of $p_{t}^{*}$ and other subsequent processes on the specific firm is suppressed in order to avoid making notation too cumbersome.
} 
$\sigma_{s e c, j}$ and $\sigma_{a g g}$. At the risk of being tedious, it is convenient to emphasize that $\sigma_{s e c, j}$ varies across different sectors, while $\sigma_{a g g}$ does not.

As firms have only incomplete information about their frictionless optimal prices, they are required to form expectations about it in between information dates. Let $z_{t}$ be the expected price discrepancy at instant $t$, conditional on information available at that time ${ }^{5}$. That is,

$$
z_{t}=\mathbb{E}_{t}\left(p_{t}-p_{t}^{*}\right)
$$

Let $\tau$ be the time elapsed since the last information date. We can decompose the firm's expected loss in period $t$ as a quadratic term on $z_{t}$ and a penalty that is incresing $\tau$. Formally, the expected loss may be written as

$$
\mathbb{E}_{t}\left(p_{t}-p_{t}^{*}\right)^{2}=\left(p_{t}-\mathbb{E}_{t} p_{t}^{*}\right)^{2}+\operatorname{Var}_{t}\left(p_{t}^{*}\right)=z_{t}^{2}+\sigma_{c}^{2} \tau
$$

where $\sigma_{c, j}^{2}=\sigma_{\text {sec }, j}^{2}+\sigma_{\text {agg }}^{2}$ is the variance of costly observable shocks (thus the subscript $c$ ). The last equality comes from the definition of $z_{t}$ as the expected discrepancy and the fact that $\mathbb{E}_{t}\left(p_{t}^{*}\right)$ is a normally distributed random variable with variance $\sigma_{c, j}^{2} \tau$, as the last information date prior to $t$ is $t-\tau$, given our definition of $\tau$. Moreover, the expected discrepancy $z_{t}$ follows an Itô Diffusion:

$$
d z_{t}=-\mu d t+\sigma_{i d, j} d W_{i d, j}
$$

The considerations above allow us, for the purpose of solving a given firms' maximization problem, to restrict our attention to the state-space $\Omega=\left\{(z, \tau) \in \mathbb{R}^{2} \mid \tau \geq 0\right\}$. Now it is clear why it is useful to define shocks to the frictionless optimal price as following Brownian Motions: it allows a parsimonious state-space representation. Processes with serial correlation (in differences) would require $\Omega$ to have more dimensions, thus making numerical methods burdensome. As already mentioned, the presence of fixed costs will define an inaction region on $\Omega$, in the interior of which the value function of the firm satisfies a standard Hamilton-Jacobi-Bellman equation (henceforth, HJB $)^{6}$ :

$$
\rho V_{j}(z, \tau)=z^{2}+\sigma_{c, j}^{2} \tau-\mu \frac{\partial V_{j}}{\partial z}(z, \tau)+\frac{\sigma_{i d, j}^{2}}{2} \frac{\partial^{2} V_{j}}{\partial z^{2}}(z, \tau)+\frac{\partial V_{j}}{\partial \tau}(z, \tau)
$$

where $j$ again denotes the economic sector to which the firm belongs and $\rho$ is the intertemporal discount rate. The value function $V$ represents not the expected value of maximized discounted profits, but rather the expected value of minimized expected costs that arise from deviations from the frictionless optimal price. Equation (3-5) must be complemented with two inequalities

${ }^{5}$ Note that, although indexed by $t, p_{t}^{*}$ is not necessarily know at that instant.

${ }^{6}$ See Stokey (2008) for a derivation. 
which are going to define the value function outside the inaction region and arise from the optimal stopping nature of the problem:

$$
\begin{gathered}
V_{j}(z, \tau) \leq \min _{z^{\prime}} V_{j}\left(z^{\prime}, \tau\right)+K_{j} \\
V_{j}(z, \tau) \leq \int_{-\infty}^{+\infty} V_{j}\left(z+\sigma_{c, j} \sqrt{\tau} y, 0\right) \phi(y) d y+F_{j}
\end{gathered}
$$

Condition (3-6) means that a firm is always allowed to pay the fixed cost $K_{j}$ and reset $z$ so as to decrease its cost while keeping $\tau$ constant. In equation $(3-7), \phi(\cdot)$ is the probability density function of a standard normal random variable. The first term on the right side is the expected value of discovering the true value of the frictionless optimal price and consequently returning to $\tau=0$. This equation means therefore that the firm may always pay the fixed cost $F_{j}$ and gather information about $p_{t}^{*}$. Equations (3-5), (36) and (3-7) consitute what is called a variational inequality. Tourin (2011) provides numerial methods for solving such problems, and appendix B contains a detailed description of the numerical methods we use for solving it.

Points on the state-space where condition (3-6) is binding constitute the region in which the optimal policy is to adjust prices. Analogously, the set where (3-7) is binding is the information gathering region of $\Omega$. It is also convenient to define the target expected discrepancy as:

$$
c_{j}(\tau)=\arg \min _{z^{\prime}} V_{j}\left(z^{\prime}, \tau\right)
$$

All firms of sector $j$ that readjust prices after being uninformed for $\tau$ periods move to the point $\left(c_{j}(\tau), \tau\right)$. Finally, it is worth noting that the variances of sectoral and aggregate shocks only appear in the maximization problem through their sum $\sigma_{c, j}^{2}$.

Figure 1 shows the price adjustment and information gathering regions, as well as $c(\tau)$, obtained by solving the maximization problem for arbitrarily specified values of the parameters. Many interesting conclusions can be drawn from it. Price adjustments occur when the expected discrepancy $z$ drifts far away from zero, as expected, and $\tau$ is relatively small. This means that firms that have not gathered information for a long period prefer to do it before resetting prices, as uninformed adjustments would be likely to be far from the actual optimal price. It is also evident from the adjustment region that uninformed price adjustments are bounded above and have little variability in size. Besides, a positive inflation rate makes it optimal for firms to place their expected discrepancies above zero when action is taken, as it is drifts downwards as time passes. Regarding the information gathering region, it is interesting to notice that it narrows down as $\tau$ grows. The interpretation for 


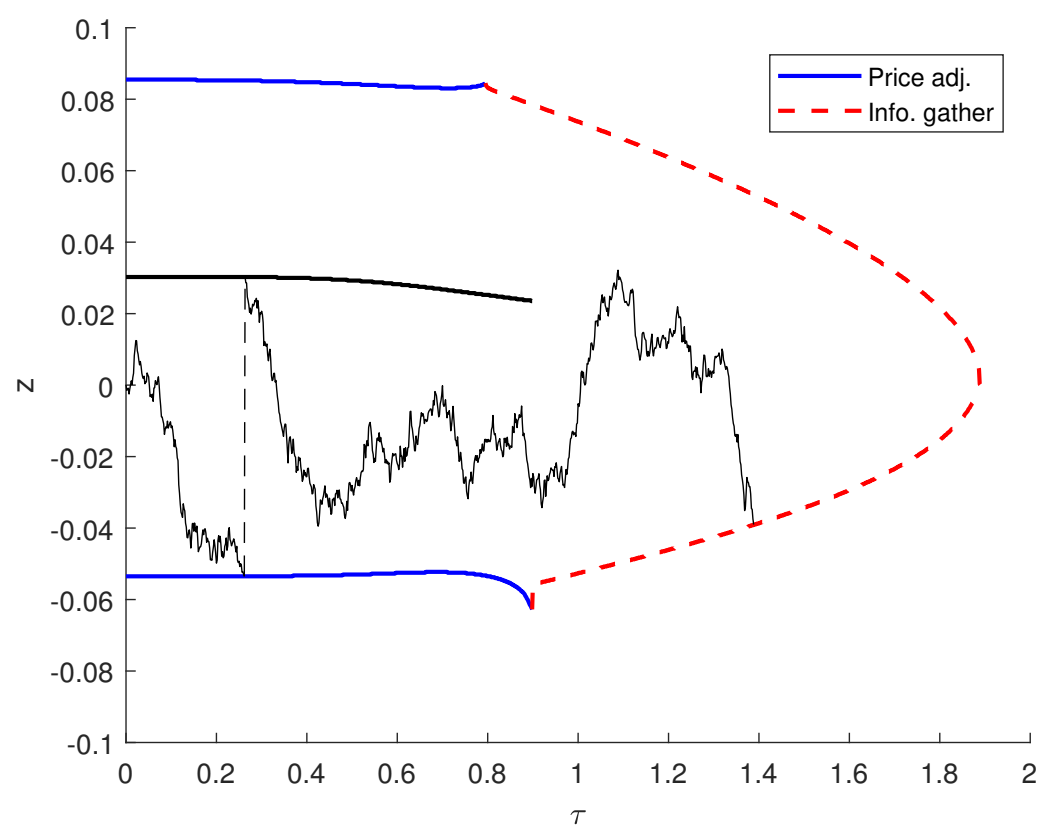

Figure 3.1: Optimal pricing policy shown as the boundary of the inaction region, for parameter values: $K=0.001, F=0.002, \mu=0.1, \rho=0.03$, $\sigma_{c}^{2}=0.05$ and $\sigma_{i d}^{2}=0.05$

this is that firms that have not collected information for long periods of time will only maintain themselves uninformed as long as their prices are close to the expected frictionless optimal prices, as otherwise the expected loss, which is linearly increasing in $\tau$, grows too large. It is also important to emphasize that informed adjustments have no upper bound. This happens because the difference between the actual frictionless optimal price and its expectation is a normally distributed random variable with variance increasing in $\tau$. We can imagine an information collecting firm as jumping to the line $\tau=0$ at a random vertical point that may be arbitrarily far away from the origin with positive probability. 


\section{Estimation}

\section{1}

\section{Estimation procedure}

We estimate the model using Simulated Methods of Moments. This method is very suitable for our purposes, since the complexity of the firms' optimization problem make it extremely hard, or maybe even impossible, to obtain analytic formulas that relate the models' parameters to its generated moments. Therefore, a simulation-based method is required. The data we employ consists of price quotes made available by UK's Office for National Statistics (ONS), which are used to construct the British CPI. It contains around 120,000 price quotes collected monthly. The time span we use in this study ranges from January 2007 to December 2017, corresponding to 120 months of data and culminating in millions of observations.

SMM estimates are the result of the following minimization process. Let $\theta \in \mathbb{R}^{n}$ denote a vector of parameters that characterize the model. Given a vector $\theta$, the model generates moments $\Psi(\theta) \in \mathbb{R}^{m}, m \geq n$, which are computed using simulated data. Also, denote by $\Psi_{\text {data }} \in \mathbb{R}^{m}$ the vector of these very same moments computed using true data. The estimated parameters are given by:

$$
\hat{\theta}=\arg \min _{\theta}\left(\Psi(\theta)-\Psi_{\text {data }}\right)^{\prime} W\left(\Psi(\theta)-\Psi_{\text {data }}\right)
$$

Estimates are consistent for any full rank matrix $W$, although some choices of $W$ are better for efficiency purposes (DeJong and Dave 2007, page 161).

Simulating a panel of firms requires initial distributions. There is no stationary distribution of firms in the state-space $\Omega$ due to the presence of aggregate and sectoral shocks, which affect several firms simultaneously. Nevertheless, a natural guess for initial densities are the ergodic distributions that would arise in the absence these disturbances, setting $\sigma_{c, j}^{2}=0$. The diffusive nature of the stochastic process that governs the evolution of $z$ makes this distribution remarkably similar to the ones that appear when aggregate and sectoral fluctuations are present. It is also very convenient that this ergodic densities $g_{j}(z, \tau)$ (which are sector-specific) can be obtained by solving a linear partial differential equation, known as Kolmogorov Forward Equation (KFE) 


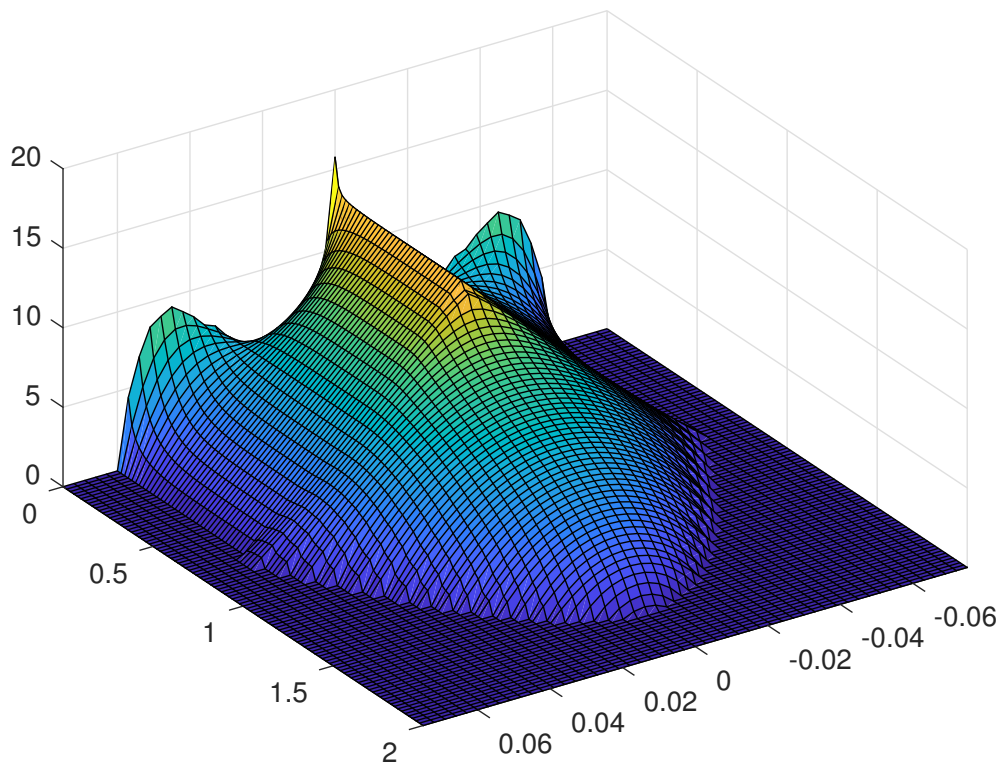

Figure 4.1: Ergodic distribution when sectoral and aggregate shocks are absent, for parameter values: $K=0.001, F=0.002, \mu=0, \rho=0.03, \sigma_{c}^{2}=0.05$ and $\sigma_{i d}^{2}=0.05$

or also as Fokker-Planck Equation:

$$
0=\mu \frac{\partial g_{j}(z, \tau)}{\partial z}+\frac{\sigma_{i d, j}^{2}}{2} \frac{\partial^{2} g_{j}(z, \tau)}{\partial z^{2}}-\frac{\partial g_{j}(z, \tau)}{\partial \tau}
$$

The equation above holds on a given point only if the density dynamics around that point depends exclusively on what happens on a neighborhood of it. To be more specific, it holds on the interior of the inaction region, except for points of the form $\left(c_{j}(\tau), \tau\right)$. This is because the distribution in a point of this form depends not only of what is going on locally around it, but also on what happens far way at the boundary of the price adjustment region, since firms that hit this boundary at $\tau$ jump to $\left(c_{j}(\tau), \tau\right)$. Fortunately, this is an easily solvable problem when using finite difference methods. Figure 2 illustrates an ergodic distribution for arbitrary parameter values.

\section{2}

\section{Moments Used in the Estimation}

Identification of the parameters of interest depends crucially on the simulated moments chosen to match those observed in the data. Moments that have a too small sensitivity to the parameters of the model may make estimation results inaccurate. Two of the model's parameters, nevertheless, are calibrated, rather than estimated. The drift of the frictionless optimal price is set at $\mu=0.0226$, which is UK's average inflation rate for the sample 
period, and the discount rate of profit is set at $\rho=0.03$.

Two models are estimated here. First, we estimate a model in which there are no different economic sectors $(N=1$ in the notation introduced above). All firms are treated as belonging to a same sector and therefore there are no sector-specific shocks, the only innovations are of aggregate and idiosyncratic kinds. This model is useful in order to illustrate that the absence of sectoral shocks may lead to unreasonably large estimates for the variance of aggregate disturbances. In this framework, there are only four parameters that must be estimated: i) the volatility of the aggregate shock $\sigma_{a g g}$, ii) the volatility of idiosyncratic innovations $\sigma_{i d}$, iii) the menu cost $K$ and iv) the information acquiring cost $F$.

The moments used for this first estimation are: i) average frequency of price adjustments, ii) mean absolute size of price adjustments, iii) squared mean absolute size of price adjustments, iv) median absolute size of price adjustments and v) standard deviation of price changes distribution. All these moments are calculated using the whole sample of firms for each month, regardless of the economic sector to which firms belong, and weighting each price quote according to its weight in the CPI construction.

The reason for picking these statistics is as follows. The frequency of price changes and mean size of price changes are directly related to the menu cost $K$ and volatility of idiosyncratic disturbances $\sigma_{i d}$. An increase in the size of menu cost $K$ would make price adjustments larger and less frequent. On the other hand, an increase in $\sigma_{i d}$ would make both the mean size and frequency of adjustments larger. This means that, all other parameters fixed, we would be able to match these statistics exactly as they appear on the data using $K$ and $\sigma_{i d}$.

The median and the stardand deviation of price changes distribution are related to the information acquring cost $F$ and $\sigma_{a g g}$. Figure 3.1 illustrates that partially informed price adjustments are not so variable in size. On the other hand, a firm that collects information may discover that its price discrepancy is arbitrarily large, which means that arbitrarily large informed price adjustments may occur with positive probability. Therefore, the costly observable shock and the information acquiring costs are related to the shape of the price adjustments distribution. Since we are already targeting the mean of the distribution, targeting the median, and hence the difference between mean and median, would give a measure of its asymmetry, while matching the standard deviation of adjustment size implies fitting the dispersion of this distribution.

Finally, the reason for choosing the the squared mean size of price 
adjustments is as follows. In the absence of aggregate disturbances, the distribution of firms in the state space would converge to an ergodic distribution as time passes. As the model approaches this stationary distribution, it would converge to a situation in which all price setting statistics are constant over time. Particularly, the mean size of price adjustments would be the same every month, except for statistical errors that arise from the fact that we have only a finite sample of price quotes. Therefore, targeting both the mean size of price adjustments and its squared value implies targeting its variance as a time series, which allows us to identify $\sigma_{a g g}$.

The second model we estimate is the multisector model, our main framework. The model's parameters are the following. For each sector, indexed by $j$, we have i) a menu cost $K_{j}$, ii) an information gathering cost $F_{j}$, iii) a volatility for idiosyncratic innovations $\sigma_{i d, j}$ and iv) a volatility for sectoral shocks $\sigma_{s e c, j}$. In addition, we also estimate the volatility of the aggregate shock $\sigma_{\text {agg. }}$. Therefore, for a model with $N$ sectors, we have $4 N+1$ parameters to estimate.

The selected moments for estimation are each sector's i) mean frequency of price changes, ii) average absolute size of price changes, iii) squared average absolute size of price changes, iv) median size of price changes and, last, v) standard deviation of the sizes of price changes. In addition, we pick all the $N(N-1) / 2$ products of mean absolute size of price changes between two different sectors. This results in $5 N+N(N-1) / 2$ moments. The rationale for the first five sets of moments is exactly the same as in the single sector case. Our choice to include the cross products of mean size of adjustments is that it allows us to match the correlation of this statistic across different economic sectors. It allows us to identify the relative size of sectoral and aggregate shocks since, if independent sectoral shocks were the only drivers of price setting decisions, all statistics would be perfectly uncorrelated across sectors. On the other hand, this correlation increases with the value of $\sigma_{\text {agg }}$. This is the information that allows us to identify the size of aggregate shocks in the multisector model.

\section{3}

\section{Estimation Results}

Estimation results for the single sector models are shown in tables 1 and 2. Table 1 shows the estimates for the parameter values and standard errors, while table 2 displays simulated moments as well as their empirical counterparts calculated using our dataset. 


\begin{tabular}{lll}
\hline \hline Parameter & Value & SE \\
\hline$\sigma_{\text {agg }}$ & 0.1987 & 0.0187 \\
$\sigma_{i d}$ & 0.0633 & 0.0013 \\
$K$ & 0.00043 & 0.00002 \\
$F$ & 1.0526 & 0.0864 \\
\hline \hline
\end{tabular}

Table 4.1: Estimated parameters and standard errors for the single sector model.

\begin{tabular}{lll}
\hline \hline Statistic & Model & Data \\
\hline Adjustment frequency & 0.1119 & 0.1127 \\
Mean adjustment size & 0.0928 & 0.0931 \\
Median adjustment size & 0.0570 & 0.0571 \\
Std. deviation of adj. size & 0.1412 & 0.1407 \\
Squared mean adj. size & 0.0092 & 0.0088 \\
\hline \hline
\end{tabular}

Table 4.2: Model generated and data moments for single sector model

Two features are salient from estimation results. First, the single sector model suggests that aggregate shocks are unreasonably volatile. In Appendix A we present a theoretical model in which the path for the aggregate shock is the nominal GDP. Using data for the sample period (1997-2016), we find that the standard deviation of UK's linearly detrended quarterly nominal GDP is $2.33 \%$, while the estimated single sector model suggests a value of $9.93 \%$ $(0.1987 / \sqrt{4}$, since the estimated value refers to yearly volatility, rather than quarterly). This is obviously a too large value, but, as we show below, the multi sector model provides much more realistic results. The second important feature is that information gathering costs are several orders of magnitude larger than menu costs. This is a consequence of the significant dispersion that characterizes the prize changes distribution. As shown in table 2 , the median size of absolute price changes is considerably below the mean size, and the standard deviation of price adjustment size is relatively large. Last, it is interesting to highlight that the model fits our data very accurately, despite having more moments to match than parameters.

We then proceed by estimating a three sector version of the model. The selected sectors are 1) Food, beverages and other agricultural products, 2) manufactured goods and 3) services. Estimates for structural parameters are displayed in table 3 , and simulated moments are shown in table 4 . It is clear 
from these results that aggregate shocks are significantly smaller than sectoral disturbances, roughly by a $4-5$ factor. Since these shocks are related to the nonergodicity of the model, this allows us to conclude that almost all the time variation of our statistics come from sectoral innovations. This is of utmost importance in the decomposition of GDP volatility that is going to be carried out in the next section. The intuition for this result is very simple in the light of our identification strategy. Although the average size of price adjustments in each sector varies significantly in time, which is why estimated sectoral shocks are large, these statistics display low correlation across different sectors.

It is inevitable to discuss here how our results are affected by the fact that we have abstracted from input-output linkages between sectors. If a sector's A output is used as an input in sector B, then shocks that affect sector A will also have an impact in sector B. This could induce a correlation in price setting statistics across sectors even in the absence of aggregate shocks. Therefore, if input-output linkages are quantitatively significant, our estimates of the volatility of aggregate shocks may feature an upward bias, and its true value would therefore be even smaller when compared to sectoral shocks.

It is interesting to notice that the sectors are significantly heterogeneous regarding not only the degree of information and price stickiness, but also the volatility of the shocks they face. As an example, foods, beverages and other agricultural products appear to have more volatile idiosyncratic shocks and smaller menu costs, which is consistent with the fact that its adjustment frequency is relatively big, while the mean size of price adjustment does not stand out. On the other hand, this sectors' specific shocks are considerably larger than the others', which is intuitive if we see primary activities as more likely to be affected by exogenous shocks, such as shifts in weather conditions, both in UK and in its trading partners.

As expected, the volatility of the aggregate shocks is considerably smaller in the multi sector model. It is remarkable that the model's nominal GDP volatility is very close to what is observed in the UK. Expressed in quarterly frequency, the model's nominal GDP volatility is $2.04 \%$ against $2.33 \%$ observed in the data. 


\begin{tabular}{lll}
\hline \hline Parameter & Value & SE \\
\hline Volat. of agregrate shocks & & \\
$\sigma_{\text {agg }}$ & 0.0408 & 0.0088 \\
Volat. of sectoral shocks & & \\
$\sigma_{\text {sec }, 1}$ & 0.2151 & 0.0117 \\
$\sigma_{\text {sec }, 2}$ & 0.1776 & 0.0097 \\
$\sigma_{\text {sec }, 2}$ & 0.1627 & 0.0122 \\
Volat. of idiosyncratic shock & & \\
$\sigma_{i d, 1}$ & 0.0865 & 0.0026 \\
$\sigma_{i d, 2}$ & 0.0564 & 0.0016 \\
$\sigma_{i d, 3}$ & 0.0480 & 0.0008 \\
Info. gathering cost & & \\
$F_{1}$ & 0.5692 & 0.0552 \\
$F_{2}$ & 0.7461 & 0.0409 \\
$F_{3}$ & 1.2173 & 0.1490 \\
Menu cost & & \\
$K_{1}$ & 0.00032 & 0.00001 \\
$K_{2}$ & 0.00060 & 0.00003 \\
$K_{3}$ & 0.00042 & 0.00001 \\
\hline \hline
\end{tabular}

Table 4.3: Estimated parameters and standard errors for the multi sector model. Sectors are numbered as follows: 1) Foods, beverages and other agricultural products, 2) Manufactures and 3) Services. For example, $\sigma_{i d, 2}$ is the volatility of idiosyncratic shocks in the manufactures sector. 


\begin{tabular}{lc}
\hline \hline Statistic & Model Data \\
\hline
\end{tabular}

\section{Adjustment frequency}

Foods etc.

$0.1744 \quad 0.1766$

Manufactures

$0.0870 \quad 0.0885$

Services

$0.0852 \quad 0.0788$

Mean adjustment size

Foods etc.

$0.0884 \quad 0.0905$

Manufactures

$0.1045 \quad 0.1025$

Services

$0.0833 \quad 0.0867$

Median adjustment size

Foods etc.

$0.0610 \quad 0.0562$

Manufactures

$0.0600 \quad 0.0673$

Services

$0.0510 \quad 0.0531$

Standard deviation of adj. size

Foods etc.

$0.1233 \quad 0.1333$

Manufactures

$0.1490 \quad 0.1526$

Services

$0.1283 \quad 0.1289$

Squared mean adjustment size

Foods etc.

$0.0082 \quad 0.0083$

Manufactures

$0.0117 \quad 0.0107$

Services

$0.0081 \quad 0.0077$

Cross product of mean adj. size

\begin{tabular}{lll} 
Foods etc. $\times$ manufactures. & 0.0093 & 0.0093 \\
Foods etc. $\times$ services & 0.0074 & 0.0079 \\
Manufactures $\times$ services & 0.0091 & 0.0089 \\
\hline
\end{tabular}

Table 4.4: Model generated and data moments for multi sector model. 


\section{5}

\section{Computational Experiments}

The estimation results displayed in the previous section allow us to perform some computational experiments regarding real GDP and sectoral output responses to aggregate and sectoral-specific, as well as these shocks' effects on output volatility. The theoretical model presented in Appendix A yields as a result the following identity:

$$
y_{t}=m_{t}-p_{t}
$$

Above, $y_{t}$ denotes real output, $p_{t}$ is the aggregate price level and $m_{t}$ is the logarithm of nominal aggregate demand, which is given exogenously as a combination of a time trend and the Wiener Process for the aggregate shock:

$$
d m_{t}=\mu d t+\sigma_{a g g} d W_{a g g, t}
$$

The first computational experiment we perform is to simulate responses of aggregate and sectoral output to nominal demand shocks. We depart from the ergodic distribution of firms that would arise in the absence of aggregate and sectoral shocks and apply a one time, unexpected shock that shifts aggregate demand from $m_{0}$ to $m_{0}+\zeta$. After this shock, $m_{t}$ evolves simply as $d m_{t}=\mu d t$.

Sectoral output responses are shown in figure 3. Our results suggest that there is significant heterogeneity in sectoral responses to aggregate shocks. In fact, services sector output takes approximately twice as long to recover from a shock than the foods and beverages sector, while manufactures lie in between the other two. This is a consequence of two features of our estimation results. First, foods and beverages face higher volatility of sectoral shocks. Since sectoral shocks are costly observable, the optimal policy for this sector features more frequent information gathering episodes. Second, this sector faces substantially lower information gathering costs, which has the same qualitative effect. This analysis follows in the exact same way for the other two sectors. On the other hand, despite this significant heterogeneity, aggregate GDP responses are similar in the single and multi sector models concerning the persistence of real effects, as shown in figure 4. Aggregate output for the multisector model is simply a weighted average of sectoral outputs, where the weights are the same as in the CPI construction. 


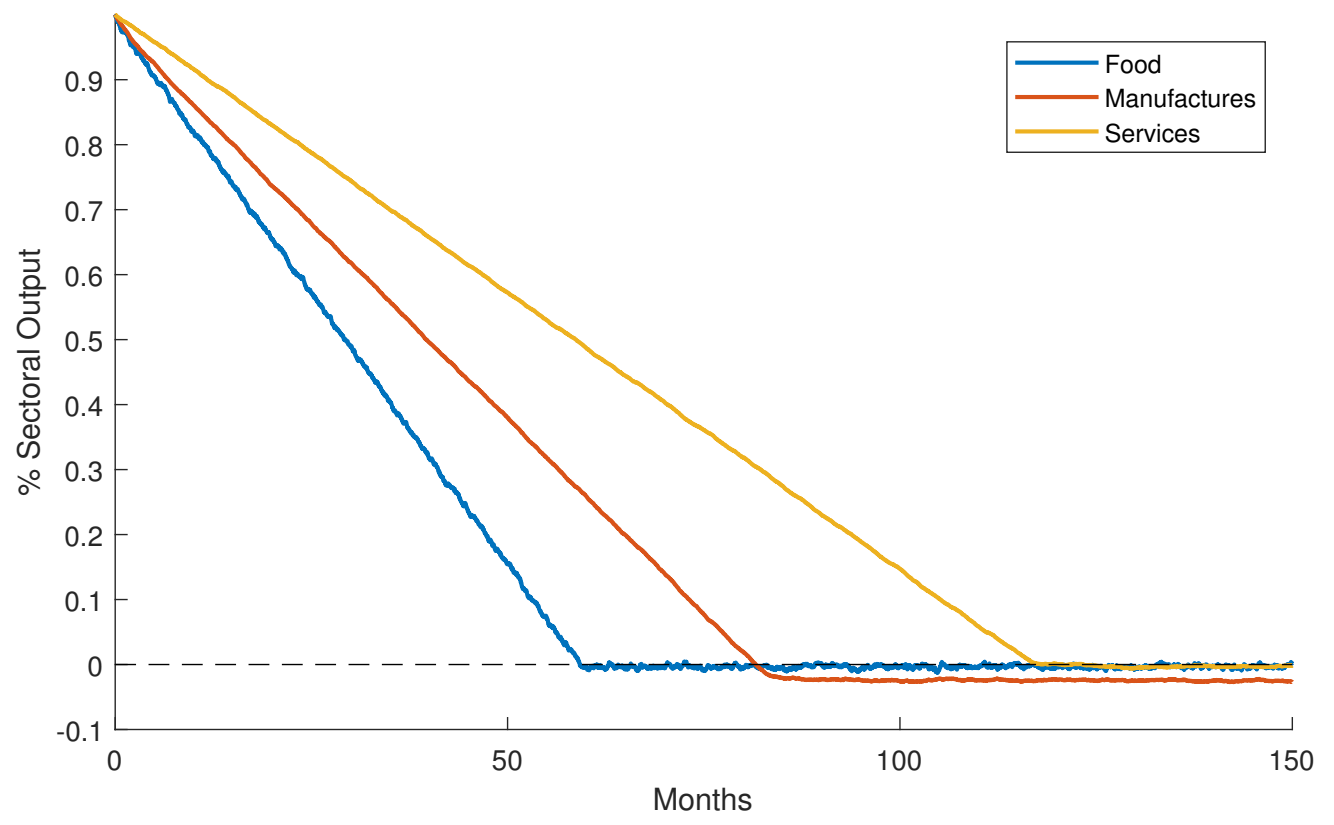

Figure 5.1: Sectoral output responses to $1 \%$ aggregate demand shocks for estimated parameter values.

Our second computational experiment consists on generating counterfactuals for real GDP volatility by varying the volatility of aggregate disturbances. In order to do this, we simulate trajectories for the stochastic processes generated by the model and compute its moments. Results, which are shown in figure 5, suggest that if aggregate shocks were shut down, real output volatility would fall by only $7.7 \%$. This suggests that the main drivers of business cycles fluctuation are sectoral, rather than aggregate shocks. As already discussed, our model abstracts from input-output linkages between economic sectors. If this linkages are quantitatively significant, our estimates for $\sigma_{\text {agg }}$ are actually upper bounds for its value. In this case, aggregate shocks would account for a even smaller fraction of economic fluctuations. 


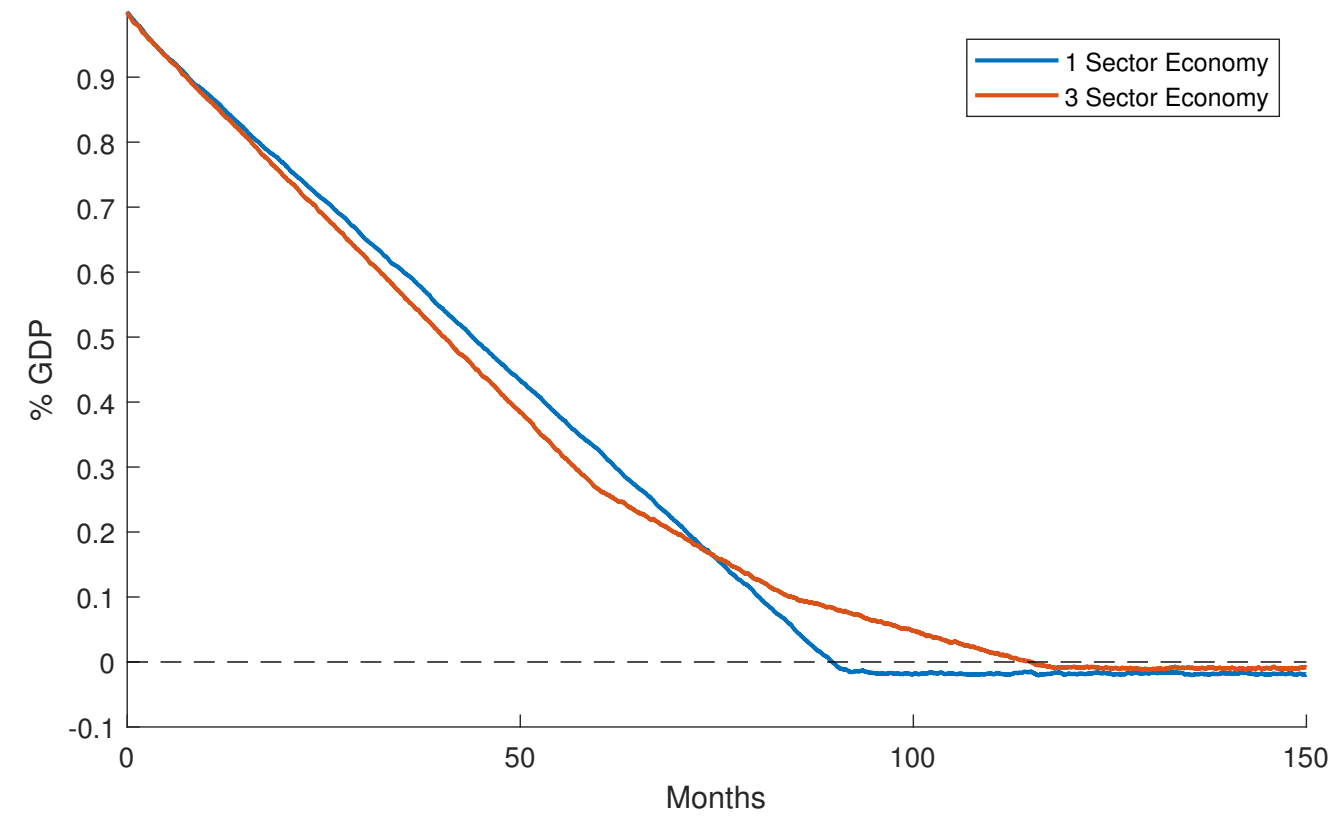

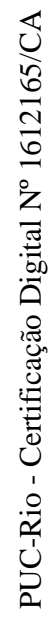

Figure 5.2: Aggregate GDP responses to one time, unexpected aggregate shocks for estimated parameter values.

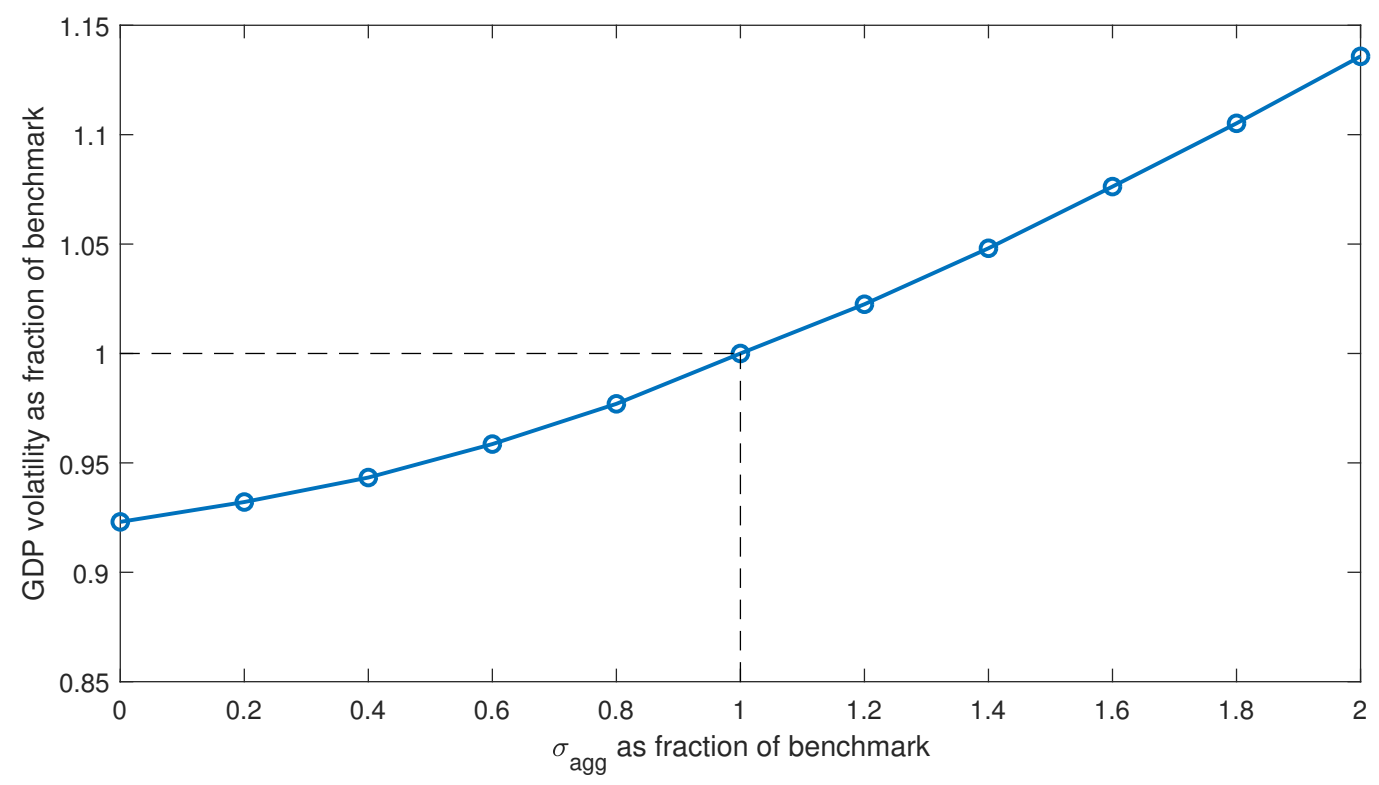

Figure 5.3: Real output volatility as a function of $\sigma_{a g g}$. The benchmark case refers to estimation results. 


\section{6 \\ Concluding Remarks}

We use price microdata to estimate a structural price setting model in order to disentangle aggregate and sectoral shocks that affect firms' pricing decisions. In order to do so, we look both at the time variation of price setting statistics and their correlation across different sectors. Our estimation results suggest that sectoral shocks are much larger than their aggregate counterparts, by factors that range from 4 to slightly more than 5 , which is our main contribution.

By estimating the same model for a single sector economy, we show that the omission of sectoral shocks and heterogeneity may lead to a substantial upward bias in the estimated size of aggregate innovations. Although this is mechanically expected to happen, it is remarkable that the multi sector model delivers a value for quarterly nominal demand volatility very close to what is observed in the data, even though this is not a targeted moment.

Finally, our estimated structural model allows us to perform some computational experiments. We show that the model suggests large heterogeneity in sectoral responses to aggregate shocks, that may be approximately twice as large in some sectors than in others. Nevertheless, the aggregate response is very similar in terms of persistence to what is obtained in a single sector model. We also show that real output volatility would be only $7.7 \%$ smaller in the absence of aggregate shocks. This suggests that sectoral shocks are the main drivers of economic fluctuations. 


\section{Bibliography}

[1] ACHDOU, Y.; HAN, J.; LASRY, J. M.; LIONS, P. L.; MOLL, B. Income and wealth distribution in macroeconomics: A continuous-time approach. NBER Working Paper No. 23732, 2017.

[2] ALVAREZ, F.; LIPPI, F.; PACIELLO, L. Optimal price setting with observation and menu costs. The Quarterly Journal of Economics 126.4: 1909-1960, 2011.

[3] ALVAREZ, F.; LIPPI, F.; PACIELLO, L. Phillips curves with observation and menu costs. Journal of the European Economic Association forthcoming, 2015.

[4] ATALAY, E. How important are sectoral shocks?. American Economic Journal: Macroeconomics 9.4: 254-80, 2017.

[5] BILS, M.; KLENOW, P. Some evidence on the importance of sticky prices. Journal of political economy 112.5: 947-985, 2004.

[6] BONOMO, M; CARVALHO, C. Endogenous time-dependent rules and inflation inertia. Journal of Money, Credit, and Banking 36.6: 1015-1041, 2004.

[7] BONOMO, M.; CARVALHO, C.; GARCIA, R. Time-and State-Dependent Pricing: A Unified Framework., 2011.

[8] BOnOMO, M.; CARVAlho, C.; GARCIA, R.; MALTA, V. Persistent Monetary Non-neutrality in an Estimated Model with Menu Costs and Partially Costly Information, 2016.

[9] CABAlLeRO, R.; ENGEL, E. Price stickiness in Ss models: New interpretations of old results. Journal of Monetary Economics 54: 100-121, 2007.

[10] CALVO, G. A. Staggered prices in a utility-maximizing framework. Journal of monetary Economics 12.3: 383-398, 1983.

[11] CAPLIN, A.; LEAHY, J. Aggregation and optimization with statedependent pricing. Econometrica: Journal of the Econometric Society: 601625, 1997. 
[12] CAPLIN, A.; SPULBER, D. Menu costs and the neutrality of money. The Quarterly Journal of Economics 102.4: 703-725, 1987.

[13] DEJONG, D. N.; DAVE, C. Structural Macroeconometrics. Princeton University Press, 2011.

[14] DUPOR, B. Aggregation and irrelevance in multi-sector models. Journal of Monetary Economics, 43(2), 391-409, 1999.

[15] FOERSTER, A. T.; SARTE, P. D. G.; WATSON, M. W. Sectoral versus aggregate shocks: A structural factor analysis of industrial production. Journal of Political Economy, 119(1), 1-38, 2011.

[16] GARIN, J.; PRIES, M.; SIMS, E. The Relative Importance of Aggregate and Sectoral Shocks and the Changing Nature of Economic Fluctuations. American Economic Journal: Macroeconomics, 10 (1): 119-48, 2018.

[17] GERTLER, M.; LEAHY, J. A Phillips curve with an Ss foundation. Journal of Political Economy 116.3: 533-572, 2008.

[18] GOLOSOV, M.; LUCAS JR., R. E. Menu costs and Phillips curves. Journal of Political Economy 115.2: 171-199, 2007.

[19] HORVATH, M. Cyclicality and sectoral linkages: Aggregate fluctuations from independent sectoral shocks. Review of Economic Dynamics 1.4: 781-808, 1998.

[20] HORVATH, M. Sectoral shocks and aggregate fluctuations. Journal of Monetary Economics, 45(1), 69-106, 2000.

[21] KLENOW, P.; KRYVTSOV, O. State-dependent or time-dependent pricing: does it matter for recent US inflation?. The Quarterly Journal of Economics 123.3: 863-904, 2008.

[22] KYDLAND, F. E.; PRESCOTT, E. C. Time to build and aggregate fluctuations. Econometrica: Journal of the Econometric Society: 1345-1370, 1982.

[23] LONG JR., J. B.; PLOSSER, C. I. Real business cycles. Journal of political Economy, 91(1), 39-69, 1983.

[24] STOKEY, N. L. The Economics of Inaction: Stochastic Control Models with Fixed Costs. Princeton University Press, 2008.

[25] TAYLOR, J. B. Staggered wage setting in a macro model. The American Economic Review: 108-113, 1979. 
[26] TOURIN, A. An Introduction to Finite Diffference Methods for PDEs in Finance, 2011.

[27] WOODFORD, M. Information-constrained state-dependent pricing. Journal of Monetary Economics 56: S100-S124, 2009. 


\section{7}

\section{Appendix A}

This appendix provides micro foundations for the firms' problem presented in section 3 . There is a representative consumer which maximizes expected discounted utility:

$$
\mathbb{E}_{0} \int_{0}^{\infty} e^{-\rho t}\left[\log \left(C_{t}\right)-H_{t}\right] d t
$$

Above, $H_{t}$ represents hours worked, $\rho>0$ is the discount factor and $C_{t}$ is a constant elasticity of substitution composite of consumption of goods produced by each of the $N$ economic sectors:

$$
C_{t}=\left[\sum_{j=1}^{N} \varepsilon_{j}^{\frac{1}{\theta}}\left(\frac{C_{j, t}}{A_{j, t}}\right)^{\frac{\theta-1}{\theta}}\right]^{\frac{\theta}{\theta-1}}
$$

where $A_{j, t}$ is a preference shifter and $C_{t, j}$ is itself a composite of goods produced by the continuum of firms that constitute each sector:

$$
C_{j, t}=\left[\int_{0}^{1}\left(\frac{C_{j, t}(i)}{Z_{j, t}(i)}\right)^{\frac{\theta-1}{\theta}} d i\right]^{\frac{\theta}{\theta-1}}
$$

Again, $Z_{j, t}(i)$ is a preference shifter. The household may save buying nominal government bonds $B_{t}$ and Arrow securities, which are omitted for simplicity. The maximization problem is thus subject to the following budget constraint:

$$
\dot{B}_{t}=r_{t} B_{t}+W_{t} H_{t}+T_{t}+\Pi_{t}-P_{t} C_{t}
$$

Above, $r_{t}$ is the interest rate, $W_{t}$ is the nominal wage, $T_{t}$ and $\Pi_{t}$ are, respectively, lump-sum transfers and firms' dividends. Importantly, the price index $P_{t}$ is suitably defined as

$$
\begin{gathered}
P_{t}=\left[\sum_{j=1}^{N} \varepsilon_{j}\left(A_{t, j} P_{t, j}\right)^{1-\theta}\right]^{\frac{1}{1-\theta}} \\
P_{j, t}=\left[\int_{0}^{1}\left(Z_{j, t}(i) P_{j, t}(i)\right)^{1-\theta} d i\right]^{\frac{1}{1-\theta}}
\end{gathered}
$$

The above specifications of the consumer problem leads to the following demand function and first order condition:

$$
C_{j, t}(i)=\varepsilon_{j}\left(A_{j, t} Z_{j, t}(i)\right)^{1-\theta}\left(\frac{P_{j, t}(i)}{P_{t}}\right)^{-\theta} C_{t}
$$




$$
C_{t}=\frac{W_{t}}{P_{t}}
$$

Regarding the supply side of the economy, the firm indexed by $i$ and belong to sector $j$ employs labor $H_{j, t}(i)$ produces good $Y_{j, t}(i)$ according to

$$
Y_{j, t}(i)=A_{j, t} Z_{j, t}(i) H_{j, t}(i)
$$

It is important to notice that the sector-level and firm-specific productivity processes, respectively $A_{j, t}$ and $Z_{j, t}(i)$, are exactly the same as the preference shifters present in (7-2) and (7-3). This assumption, which follows Woodford (2009), is, although arbitrary, necessary for the derivation of the quadratic approximation of the loss function. Its only purpose is to make the firms' problem simpler and tractable.

The frictionless optimal price $P_{j, t}^{*}(i)$ in this setting is thus the marginal cost of the firm increased by a constant mark-up, which, already substituting for (7-8), becomes:

$$
P_{j, t}^{*}(i)=\frac{\theta}{1-\theta} \frac{P_{t} C_{t}}{A_{j, t} Z j, t(i)}
$$

To complete the model, we assume that the central bank acts as to make the logarithm of nominal aggregate demand $P_{t} C_{t}$ follow a Brownian Motion and that sector- and firm-level productivity also follow processes of this same kind. Taking logarithms in equation (7-10) gives us the same stochastic processes for the frictionless optimal price as described in the main text. Regarding the derivation of the quadratic approximation for the firms' loss function, it is exactly the same as the one presented in Bonomo et al. (2018). 


\section{8 \\ Appendix B}

This appendix contains a description of the finite difference method used to solve the variational inequality presented in the main text. It is based on Achdou, Han, Lasry, Lions and Moll (2014), Tourin (2011) and Bonomo et al. (2018).

First, it is necessary to define discrete grids for $z$ and $\tau$. We opt for using equally spaced grids for simplicity: $\left\{z_{1}, z_{2}, \ldots, z_{I}\right\}$ and $\left\{\tau_{1}=0, \tau_{2}, \ldots, \tau_{J}=\bar{\tau}\right\}$, where $z_{i+1}-z_{i}=\Delta z$ and $\tau_{j+1}-\tau_{j}=\Delta \tau$ are constant. Define also $V_{i j}=V\left(z_{i}, \tau_{j}\right)$. The following finite difference approximations for partial derivatives are used:

$$
\begin{array}{r}
\frac{\partial V\left(z_{i}, \tau_{j}\right)}{\partial z} \approx \frac{V_{i, j}-V_{i-1, j}}{\Delta z} \\
\frac{\partial^{2} V\left(z_{i}, \tau_{j}\right)}{\partial z^{2}} \approx \frac{V_{i+1, j}-2 V_{i j}+V_{i-1, j}}{\Delta z^{2}} \\
\frac{\partial V\left(z_{i}, \tau_{j}\right)}{\partial \tau} \approx \frac{V_{i, j+1}-V_{i, j}}{\Delta \tau}
\end{array}
$$

It is also necessary to assume that the diffusion process which governs the evolution of $z$ reflects at $z_{1}$ and $z_{I}$. There is no problem with such assumption as long as the grid of $z$ is large enough to include the whole inaction region, which means that the boundaries of the grid are never reached by any firm.

The algorithm goes as follows. We start with a guess for $V(z, 0)$, discretized as $V_{i, 1}^{0}$, and choose the last grid point $\bar{\tau}$ large enough so that the optimal decision at $\tau=\bar{\tau}$ is to gather information, which implies that the discrtized version of equation (3-7) holds with equality:

$$
V_{i, J}^{n+1}=\sum_{k=1}^{I} V_{k, 1}^{n} \frac{1}{\sigma_{c} \sqrt{\tau_{j}}} \phi_{i j}\left(\frac{z_{k}-z_{i}}{\sigma_{c} \sqrt{\tau}}\right) \Delta z+F
$$

We then proceed backwards for $\tau<\bar{\tau}$ by solving the implicit scheme: 


$$
\rho V_{i, j \mid i n}^{n+1}=z_{i}^{2}+\sigma_{c} \tau_{j}-\mu \frac{V_{i, j \mid i n}^{n+1}-V_{i-1, j \mid i n}^{n+1}}{\Delta z}+\frac{\sigma_{f}^{2}}{2} \frac{V_{i+1, j \mid i n}^{n+1}-2 V_{i, j \mid i n}^{n+1}+V_{i-1, j \mid i n}^{n+1}}{\Delta z^{2}}+
$$

Above, "in" refers to inaction, since this is the value function of a firm that decides not to adjust prices or gather information. Reflection at the boundaries mentioned above implies $V_{0, j \mid i n}^{n+1}=V_{2, j \mid i n}^{n+1}=$ and $V_{I+1, j \mid i n}^{n+1}=V_{I-1, j \mid i n}^{n+1}=$ for all $j$, and equation (8-1) boils down to a linear equation that allows us to obtain $\left\{V_{i, j \mid i n}^{n+1}\right\}_{i=0}^{I}$ from $\left\{V_{i, j+1}^{n+1}\right\}_{i=0}^{I}$.

It is necessary to impose conditions (3-6) and (3-7). Define:

$$
\begin{gathered}
V_{i, j \mid a d j}^{n+1}=\min _{i} V_{i, j \mid i n}^{n+1}+K \\
V_{i, j \mid \text { info }}^{n+1}=\sum_{k=1}^{I} V_{k, 1}^{n} \frac{1}{\sigma_{c \sqrt{\tau_{j}}}} \phi_{i j}\left(\frac{z_{k}-z_{i}}{\sigma_{c} \sqrt{\tau}}\right) \Delta z+F
\end{gathered}
$$

Conditions (3-6) and (3-7) therefore become:

$$
V_{i, j}^{n+1}=\min \left\{V_{i, j \mid i n}^{n+1}, V_{i, j \mid a d j}^{n+1}, V_{i, j \mid i n f o}^{n+1}\right\}
$$

The value which minimizes the right hand side of the above equation determines whether the optimal decision for a firm at point $\left(z_{i}, \tau_{j}\right)$ is to stay inactive, adjust prices or collect information. 